\title{
Functionalism in Translation: A Case Study Investigation into Translation literature based on Nord's Documentary vs. Instrumental Dichotomy
}

\author{
Maryam Arbabi $^{1^{*}} ;$ Mehrdad Vasheghani Farahani $^{2}$ \\ Islamic Azad University, Central Branch, Tehran, Iran ${ }^{1}$; Leipzig University, Germany ${ }^{2}$ \\ *Corresponding author: arbabi22@gmail.com
}

\begin{abstract}
The main objective of the current study was to analyze a Persian Translation of a short story from functionalism perspective and Documentary vs. Instrumental Dichotomy. To this end, the Persian translation of the book titled "The Little Prince" was analyzed and compared with its English version (indirect translation from French) to see if the Persian translation was more documentary or instrumental oriented in nature. The theoretical framework of the study was Nord's dichotomy of instrumental vs. documentary translation. The book was analyzed at the sentence and above sentence level and covered the whole book. As the qualitative analysis showed, the translation of the book was instrumental oriented, and the book reads like an original in the target language.
\end{abstract}

Keyword: Translation; Functionalist Approaches; Documentary Translation; Instrumental Translation; Source Text; Target Text.

\section{Introduction}

Since the 1970s, there has been an interest in translating children's book. Indeed, studies in different fields of studies have made a great amount of contribution to children's literature and translating children's literature; however, fewer studies have been done with the purpose of studying the underlying layers of children's literature translation (Lathey, 2010). Children's literature as a genre whose boundaries is sometimes breached by adult's literature (Lathey, 2016) 'is not just a peripheral literary phenomenon: in the dynamics of the literary field, it fulfills a basic role specifically in the establishment of canons' (Coillie \& Verschueren, 2006, p. 19). Although there is much disagreement on the definition of children's literature, it is basically defined by (Chang, 2007) as 'a body of texts that is intended to for a particular readership, that is, children, children being defined loosely in terms of a range of socio-cultural and individual characteristics' (p.8). Children's literature and children's books, as a specific genre, share some unique features. As a matter of fact, 
children's books are shorter and have more colures and cartoons than adults' books. This is supported by (Hollindale, 1997) who says,

\begin{abstract}
'tend to favour an active rather than a passive treatment, with dialogue and incident rather than description and introspection; child protagonists are the rule; conventions are much used' the story develops with a clearcut moral schematism which much adult fiction ignores.' (p.36)
\end{abstract}

\title{
Functionalism
}

Functionalism is a theory in translation which was put forward by Vermeer (1996). Functionalism as a model of translation analysis has been the focus of researchers in recent years. Functionalism in translation was the focus of study and interest for scholars like Nord, Mantori, and Reiss (Yi, 2013). These researchers and translators put forward the view that translation cannot be restricted to such old concepts as equivalence and/ or literal vs. free translation. They rather thought that any translation has a purpose and faction which has to be determined prior to the translation itself. According to functional translation theories, the main factor in choosing the translation method is the constraints of the target texts as stated by Nord (1991) that 'translation is the production of a functional target text maintaining a relationship with a given source text that is specified according to the intended or demanded function of the target text' (p. 28).

Based on the view of functional translation theories, in order to make a translation proper; some linguistic and stylistic criteria are required including accuracy, syntax, sentence structure complexity, stylistic qualities and grammaticalness (Kriston, 2014). It is very important that the translator takes all of these features into consideration; otherwise, the target text will become a translation which is functionally inadequate.

\section{Equivalence and Equivalence Relation}

Finding an appropriate equivalence which can transfer the meaning from source text (ST) into target text (TT) has always been a hot debate in the field of translation and translation theories (Boushaba, 1988). This debate is mainly due to the fact that (Sokolovsky, 2010) 'the relations between the original text and translation text are quite complex' (P.285) and one cannot ensure the full transfer of the message from ST into TT. In order to eschew the old conflict between literal and free translation, scholars in 1950s and 1960s embarked on more systematic efforts to analyzing texts. 
The most important efforts revolved around the issue of equivalence (Munday, 2014). As a term which is believed by some scholars to be the cardinal problem of translation (Catford, 965), equivalence in its simple form, is defined as "the nature and the extent of the relationship which exists between SL and TL texts or smaller linguistic units" (Shuttleworth \& Cowie, 1997, p. 49). In line with this definition, Palumbo (2009) defined equivalence as "the relationship existing between a translation and the original text"(p.42). When considering translation as a productoriented phenomenon, a significance focus is, therefore, put on the relationship between translation and its source text (Williams, 2013). This binary classification, that is to say, source text or target text orientation is according to Pym (2010) 'deeply anchored in Western nationalism' (p.34) and is not seen in other parts of the world.

One of the first scholars who tried to provide a category of equivalence was the Russian Linguist, Jakobson (Munday, 2001). According to Venuti (2012) Being a formalist and structuralist linguistic, Jakobson, labeled translation equivalence into three categories of

1: Intralingual translation or rewording is an interpretation of verbal signs by means of other signs of the same language.

2: Interlingual translation or translation proper is an interpretation of verbal signs by means of some other language.

3: Intersemiotic translation is an interpretation of verbal signs by means of signs of nonverbal sign systems. (p. 127).

What distinguishes this category form other ones of the same ilk is the linguisticallyorientation of this category. For him, everything which is in one language can be transferred into another language' except for poem which requires some sense of creativity (Ibid). He also believes equivalence in difference as a major concern for scholars and according to (Munday, 2001) 'the cardinal problem of language and the pivotal concern of linguistics' (p.37).

Jakobson was not the only scholar who adapted a linguistically- oriented approach towards defining translation equivalence. Working for many years as the Bible translator, Nida felt, by bone, the translation problems and tried to propose a model to overcome them. Adapting Chomsky's theory of transformational grammar and the notion of Kernel sentence (Pym, 2010), Nida proposes two main types of translation equivalence as formal correspondence and dynamic equivalence. For him, a formal correspondence, as Nida (1964) says 'focuses attention on the message itself, in both form and content, unlike dynamic equivalence which is based upon 'the principle of 
equivalent effect' (p. 159). However, Nida \& Taber (1982) define dynamic equivalence as,

'a translation principle according to which a translator seeks to translate the meaning of the original in such a way that the TL wording will trigger the same impact on the TL audience as the original wording did upon the ST audience.' (p. 200)

For Nida, the dynamic equivalence has priority over formal correspondence. This is mostly due to the fact that by following dynamic equivalence, the message is transferred into the target language in a way that the receptor response is equivalent to that of the source text (Kerr, 2011). The long-lasting debate to select from either formal correspondence or dynamic equivalence is rooted in source or target text propensity of the translators. The older view emphasized on the adherence to the source text in terms of structure and lexis. Indeed, as Nida\& Taber (1969) say, in contrary to the old focus of translation which emphasized on the form of the message,

'The new focus, however, has shifted to the response of the receptor. Therefore, what one must determine is the response of the receptor to the translated message. This response must then be compared with the way in which the original receptors presumably reacted to the message when it was given in its original setting.' (p.1)

Popovic, a linguistic and translator, also distinguishes between four main types of translation equivalences. He proposes (Dewi, Indrayani \& Citraresmana, 2014) this category based on the similarities and differences between two languages in terms of structures and cultures.

'1. Linguistic equivalence, where there is homogeneity on the linguistic level of both SL and TL texts, i.e. word for word translation.

2. Paradigmatic equivalence, where there is the equivalence of 'the elements of a paradigmatic expressive axis', i.e. elements of grammar.

3. Stylistic (translational) equivalence, where there is 'functional equivalence of elements in both original and translation aiming at an expressive identity with an invariant of identical meaning'.

4. Textual (syntagmatic) equivalence, where there is the equivalence of the syntagmatic structuring of a text, i.e. equivalence of form and shape' (p. 110).

In addition, Catford (1965) distinguishes between two main types of translation equivalence as a formal correspondent and textual equivalent. His dichotomy of 
translation equivalence is mostly based on the ideas of types and shifts in translation (Panou, 2013). From one hand, the textual equivalence is 'any TL text or portion of text which is observed on a particular occasion ... to be the equivalent of a given SL text or portion of text Catford' (p. 27). As the definition implies, textual equivalence is more based on the constraints of TT and is used mostly when the translator tries to adhere to the TT. From the other hand, a formal correspondent 'is any TL category (unit, class, structure, element of structure, etc.) which can be said, to occupy, the 'same' place in the 'economy' of TL as the given SL category occupies in the SL' ( $p$. 27).

In conclusion, it can be said that paradigm of equivalence is source languageoriented and looks to find a one to one correlation based on the constraints of ST. What is important in this paradigm is to find an equivalence which can produce the same effect as close as possible to the source language, where the message was produced (Xiang, 2011).

\section{Functionalism and Theories of Translation}

During the 1970s, there came a steady movement from purely linguistic typologies and theories of translation towards functional theories in analyzing translation. This movement which flourished mostly in Germany was an effort to embark on new paradigms in Translation Studies (Munday, 2001). As a matter of fact, according to As-Safi (2011) the 1970s and 1980s,

'witnessed a shift from the static linguistic typologies of translation and the emergence, in Germany, of a functionalist and communicative approach to the analysis of translation. These theories subsume the early work on text type and language function, the theory of translational action, skopos theory and text analysis model.' (p.33)

What functional theories of translation have all in common is that translation as a purposeful activity and communicative action is determined in the socio-cultural context of the target translation (Nord, 2010). In other words, the proponents of functional theories of translation saw translation, as opposed to purely linguistic theories, in accordance with the function of translation and the role it can have in the socio-cultural context of the target language. Indeed, apart from debates over the style or the type of equivalence and translation strategy, functional theories put forward the idea that (Superceanu, 2009), 
'in a context different from that for which they were originally produced. The new context filled with people who have specific knowledge, expectations, and needs may require a translation which preserves the content, style, and function of the ST, but which may equally require a freer translation, an adaptation of the ST, which will be appropriate as long as it reaches its audience.' (p. 17)

What is very important for functionalism in translation is the issue of a good translation. According to this view (Yue, 2013) a good translation is possible when it can 'deliver the source text meaning as well as the source-culture embedded in the language and the audience of the target language and target-culture feel the same way as the source text audience about the text' (p. 61). This command of good translation does not, therefore, limits itself to archaic dichotomies of translation like the literal vs. free translation.

\section{Skopos and Katharina Reiss's Text Typology of Translation}

Reiss's work on text typology of translation mainly stems from her works and studies on text analysis beyond sentence level and at the whole text. In this regard, translation is not a mere replacement of source text materials into target text; rather, it is defined (Nord, 1997) as 'the production of a functional TT maintaining a relationship with a given ST that is specified according to the intended or demanded function of the TT (translation skopos)'. (p.28). Her idea of text typology was inspired by Butler's three main functions of language which are an informative function, expressive function and appellative function (Bühler, 1990). In her text typology, function and the purpose of the translation play the very crucial role. Therefore, as (Snell-Hornby, 2006) say,

'The most important factor is the Skopos (Greek for aim, purpose, goal), hence the purpose or function of the translation in the target culture, as specified by the client (in a translation brief) or the envisaged userexpectations; translation is hence prospective rather than, as had hitherto been the case, retrospective.' (p.54)

Table 1. Functional characteristics of text types and links to translation methods (Munday, 2015, p. 115).

\begin{tabular}{llll}
\hline \multicolumn{1}{c}{ Text Type } & \multicolumn{1}{c}{ Informative } & \multicolumn{1}{c}{ Expressive } & \multicolumn{1}{c}{ Operative } \\
\hline Language & Informative & Expressive & Appellative (making an \\
function: & $\begin{array}{l}\text { (representing } \\
\text { objects and facts) }\end{array}$ & $\begin{array}{l}\text { (expressing } \\
\text { sender's attitude) }\end{array}$ & appeal to text receiver)
\end{tabular}




\begin{tabular}{|c|c|c|c|}
\hline $\begin{array}{l}\text { Language } \\
\text { Dimension }\end{array}$ & Logical & Aesthetic & Dialogic \\
\hline Text focus & Content-focused & Form-focused & Appellative-focused \\
\hline TT should & $\begin{array}{l}\text { Transmit } \\
\text { referentially } \\
\text { content }\end{array}$ & $\begin{array}{l}\text { Transmit aesthetic } \\
\text { form }\end{array}$ & Elicit desired response \\
\hline $\begin{array}{l}\text { Translation } \\
\text { method }\end{array}$ & $\begin{array}{l}\text { Plain prose, } \\
\text { exploitation as } \\
\text { required }\end{array}$ & $\begin{array}{l}\text { Identifying' } \\
\text { method, } \\
\text { adopt perspective } \\
\text { of ST author }\end{array}$ & $\begin{array}{l}\text { Adaptive, equivalent } \\
\text { Effect }\end{array}$ \\
\hline
\end{tabular}

As the table 1 shows, Reiss distinguishes between three main types of language function; each with its own translation strategy. Informative texts include texts like documents or deeds and the translator has to translate the referential meaning. Expressive texts are written to express a piece of fact like biographies in which the translation strategy is to transmit aesthetic form. The last type is operative in which the writer tries to persuade the reader and the translation model is the adaptive or equivalent effect.

\section{Translation Action}

Translation Action theory which was proposed by Holz-Manttari is also regarded as another theory related to functional theories of translation. Like Skopos, translation action views translation as a target-driven activity. In this kind of translation, (HolzManttari, 1984) the purpose 'is not about translating words, sentences or texts but is in every case about guiding the intended co-operation over cultural barriers enabling functionally oriented communication'. (p. 7-8). According to this view of translation, the aim of the translation is basically determined not just by the equivalence; rather by the function and it is the function and/ or the purpose of the translation which determines other criteria. In order to embark on a translation task, Mantori (ibid) introduces various stages which have to be cautiously taken by the translator. Indeed, each of these stages has an impact on each other and all have to be taken seriously to produce a target text which is functionally adequate.

the initiator: the company or individual who needs the translation;

the commissioner: the individual or agency who contacts the translator;

the ST producer: the individual(s) within the company who write(s) the ST, and who are not necessarily involved in the TT production;

the TT producer: the translator(s) and the translation agency or department; 
the TT user: the person who uses the TT - for example, a teacher using a translated textbook or a rep using sales brochures;

the TT receiver: the final recipient of the TT - for example, the students using the textbook in the teacher's class or clients reading the translated sales brochures.

\section{Skopos Theory}

Skopos is the term with a Latin root which means purpose. Skopos theory in translation was first introduced by Vermeer in 1970s to point to the notion of translation as a purposeful activity (Munday, 2012). A major criterion for Skopos theory is that translation has to be functionally adequate in a sense that its purpose is predetermined by the translation commissioner (ibid). Nord (1997) says that

'Each text is produced for a given purpose and should serve this purpose. The Skopos rule thus reads as follows: translate/interpret/speak/write in a way that enables your text/translation to function in the situation it is used and with the people who want to use it and precisely in the way they want it to function' (p. 29).

It goes without saying that $(\mathrm{Du}, 2012)$ 'the prime principle determining any translation process is the purpose (Skopos) of the overall translational action' (p.2190). As a result, it is the translation purpose (Skopos) which determines translation style, techniques and strategies and the translator is required to aware of it (Molina \& Albir, 2002). In this regard, translation is considered as the offer of information from the source into target text which is secondary to the source text (Jabir, 2006).

\section{Research Questions}

Regarding the aforementioned issues in translation and children's literature, the current research was an attempt to answer the following question.

1: What is the main translation approach in the translation of the Little Prince from English into Persian? 


\section{The Corpus of the Study}

The corpus of the current study consisted of a well-known book written for children; that is to say, "The Little Prince". This book is considered as a classical work for children and has been translated into many languages. An Iranian well-known translator Ahmad Shamloo did its Persian translation. Since the original book was written in French, this research relied on the indirect translation which was from English (Source text) to Persian (Target text). For the level of analysis, it is worth mentioning that the level of analysis was the sentence and above sentence level so that the translation could be analyzed in accordance with the theoretical framework.

\section{Theoretical Framework}

As far as the theoretical framework was concerned, the present study enjoyed Nord's (1991) translation dichotomy of documentary vs. instrumental translation. The distinction between these two models refers to the function (s) that the source text and the target text may have (Munday, 2016). Also, one advantage of Nord's model of text analysis is that it does not limit itself to one or two text types; rather one can apply her model to all text types. In this regard, for Nord (2005), documentary translation
'serves as a document of an SC communication between the author and the ST receiver; whereas the instrumental translation is a communicative instrument in its own right, conveying a message directly from the ST author to the TT receiver. An instrumental translation can have the same or a similar or analogous function as the ST.' (P.80)

According to this model, in any documentary translation, some aspects of the source text are transferred and retained into the target text; so that the target text looks like as a dependent text of the source text (Xuedong, 2014). Examples of documentary translation can include literal or exoticizing translations. Instrumental translation can, however, be used in texts or situations that can functionally serve the same purpose of the source text while the reader of the text is not aware of reading a text which was written in a different form in another language. Nord (2005) distinguishes between three main forms as bifunctional translation in which the source text and the target text can functionally serve the same purpose; heterobifunctional in which the target text and the source text functions cannot be fulfilled, and the translator has to make some adaptations. The last form is called homologous in which the target text is intended to have similar effects on the source text literary context. 
In order to have the model of documentary vs. instrumental translation into practice, several processes have to be passed. The model necessitates two types of analysis; that is to say, external factors analysis and internal factors analysis. External factors include such parameters as

Sender: Nord (1991) makes a distinction between the sender of the text and the producer of the text. For her,

'The sender of a text is the person (or institution, etc.) who uses the text in order to convey a certain message to somebody else and/or to produce a certain effect, whereas the text producer writes the text according to the instructions of the sender, and complies with the rules and norms of text production valid in the respective language and culture.' (p. 43)

Sender's intention: Intention of the sender determines the way text is structure. The sender's intention regulates the purpose he or she wants to achieve.

Audience: Audience refers to the receiver of the text and the people who will be addressed by the translator in the target text. Nord (2005) makes a distinction between audience and chance receiver. The former is the person who is addressed by the translator; while the latter can be anyone who happens to read the translation.

Medium/ Channel: it refers to the way the text is conveyed to the reader.

Place of Communication: By this, Nord refers to both the place of text production and the place of the reception.

Time of communication: Time of communication refers to the time when the source text is produced and the time when the text is translated into the target language.

The motive for communication: It highlights not only the reason for the publication of the text, but also for the reasons and occasions the text has been produced.

Text function: The role that a piece of text can play in a situation. Nord (ibid) asserts that the text function and genre of the text can be very similar and correlated; albeit, the differences they can have.

The second phase of text analysis is the internal factors which include the following:

Subject Matter: Nord (ibid) considers subject matter as a fundamental prerequisite for analyzing text linguistics. Subject matter refers to the extent to which the translation is culturally oriented to source text or target text. 
Content: For Nord, content means the reference of the text such as cohesion and connotation.

Presupposition: It refers to the presupposed and/or background knowledge that the sender or the receiver of the text has.

Text Composition: According to Munday (2016) text composition includes both microstructure and macrostructure elements. The latter includes such elements as stages of the plot, units of information and the latter include elements like footnotes, citations, and endnotes.

Nonverbal Elements: Such elements as figures, illustration, italics and...

Lexis: Features like register, dialect and subject-specific terminology (Munday, 2004).

Sentence Structure: The way sentences are arranged in the text like length and their rhetoric.

Suprasegmentally Features: Features like tone, intonation, stress, and pitch.

\section{External Factor Analysis of the Source and Target Texts}

As said, the model of Nord necessitates two levels of analysis; that is to say, external analysis and internal analysis. In this study, first the external analysis is carried out, then the internal one.

\section{Source Text External Analysis}

Sender's intention and the subject matter of the source text: As far as the sender's (author) intention is concerned, the purpose of the writer was to write a book for the children and for the youth.

Audience: As said, the main audience of this book is the children and the youth. A fleeting look at the theme of the book can reveal the fact that it is a book written for the children and the youth.

Medium: The source text in English is written in 64 pages with illustrations and colorful photographs on each page to make it more interesting for children and the youth. It is a book which has a mysterious (but simple in structure) language replant 
with pictures to make it more comprehensible for the children and for the youth. Since the book in intended to meet the needs of the children and the youth, it is written in a very simple language; no sophisticated structures are used and the vocabularies are easy to understand.

Place of Communication: The text was translated in England by Katherine Woods

Time of the Communication: The text was translated into English in 1943.

The motive for communication: The source text has the objective of entertaining the children and the youth and also familiarizing the readers with the basics of philosophy. The author made effort to familiarize the readers with such basics as friendship and moralities. Also, the motive of the writer is that in 1953, the pilot of an airplane crashed into a dessert and had to land in the middle of the desert. This accident motivated him to write a story about this adventure in which he saw a little boy who came from a distant planet.

Text Function: The function of the text is somehow expressive in which the author used creative composition and easy grammatical structures and words. The source text also enjoys the aesthetic aspects of language.

\section{Target Text External Analysis}

Sender's intention and the subject matter of the target text: The target text into Persian (Farsi) has the same purpose as the source text; that is to say, it is translated to meet the needs of the children and the youth in Iran. In other words, the target text is purpose preserving.

Audience: Like the source text, the target text also is translated into Persian to meet the needs of the children and the youth. Indeed, the source and the target texts have the same function in nature.

Medium: The target text has been written in 43 pages. Although the number of pages differs, the source text has been translated fully into Persian. The pictures in target text differ from those of the source text. Actually, the pictures in the source text are bigger than the ones in the target text. Also, while the pictures in the source text are appeared colorful, the pictures in the target text are both black and white and colorful. In addition, the pictures are not the same; meaning that the target text has some extra pictures. As far as the language is concerned, the target text is also very easy to understand and the length of the sentences is more or less the same as the target text. 
Place of Communication: The target text was produced by a very well-known writer, poet, and translator, Ahmad Shamloo in Iran.

Time of the Communication: The target text was produced in 1984 in Iran.

The motive for communication: As in the source text, the target text has the purpose of amusing the children and the youth and familiarizing them with the principals of moralities. However, as a humanist, the Iranian translator was motivated by the fact that human beings and their relations are very important characteristics of every single man. For him, respecting people and their values are the very basics of ethics.

Text Function: Like the source text, the target text has the function of expressive and creative composition. However, the target text is more of a prose-oriented in nature and it reads well and fluently in Persian as compared to its source text.

An overview of the external analysis of the source text and the target text showed that they are more or less different in terms of the external analysis items. In other words, the target text does not preserve the source text and the translator made an endeavor to make some changes and reshape the source text.

\section{Source and Target Texts Internal Factor}

\section{Presupposition}

By definition (Yule, 2010) the presupposition is 'an assumption by a speaker/ writer about what is true or already known by the listener/reader'(p. 293). The problem of presupposition is that it is not a clear notion; rather it is such a complicated phenomenon that differs from one person/ culture to another one (Nord, 2005). According to this model of text analysis (Nord, 2005) texts, from presupposition point of view, are either factual or fictional. The factual texts are the ones which 'claim to make a presupposition about reality; while the fictional texts "make no such claim' (p.107). Based on this dichotomy, the source text and target texts are classified as fictional; mainly due to the fact that they make no such a proposition about reality. Nord, furthermore, points to the fact that one way of spotting the presupposition is to look for the redundancies in either the source or the target text.

Given the fact that the target text is about a small boy with his snack, and also since the texts are considered as fictional in nature, the author of the source text has left some notions unexplained like "boa constrictor"; while in the Persian translation, the translator has added the word "Snack" in order to make it clear to the reader. Another 
example is the word Arizona which is referred to a state in the USA in the sentence "I can distinguish China from Arizona" or the phrase "in the Desert of Sahara" in the sentence "I had an accident with my plane in the Desert of Sahara," in which the writer presupposes that the reader is already of the name. The translator has tried, however, to make these expressions clearer to the readership in the Persian language; in such a way that it is an expression written in Persian.

\section{Lexis}

By lexis, Nord (2005) refers to a broad range of criterion like syntactic, semantic, structural, collocational and pragmatics aspects of words. In this regard, the source texts have a number of characteristics which distinguishes it from other genres. First, the source text is narrated in the form of the first-person narrative in which the author frequently uses the pronouns "I" and "We".

Examples:

I had never drawn a sheep

took out of my pocket a sheet of paper

While we have been talking together a month has gone by

The extensive usage of self- pronouns is an important characteristic of literary works which makes them distinguished from scientific texts. In addition, due to the extensive usage of self-pronouns, there is not any track of passive structures that are used in scientific papers. In addition, the usage of "I" reveals that the author stands in the position of the sender of the message. From the text analysis perspectives, it is already clear that the author is well aware of the conventions of these genres and has tried to use the conventions relating it. The same phenomena can be seen in the translation of the text and most of the conventions, text specifications and structures have been remained unchanged in Persian translation.

Table 2. Pronoun Frequency in English and Persian

\begin{tabular}{ccc} 
Pronoun & English & Persian \\
\hline I & 547 & 212 \\
You & 296 & 192 \\
He & 303 & 60 \\
She & 50 & 60 \\
It & 265 & 137 \\
We & 23 & 18 \\
They & 97 & 23 \\
Us & 11 & 1
\end{tabular}




\begin{tabular}{ccc} 
Me & 152 & 0 \\
My & 163 & 212 \\
Mine & 1 & 0 \\
Yours & 6 & 3 \\
His & 121 & 65 \\
Him & 77 & 9 \\
Hers & 0 & 9 \\
Her & 27 & 9 \\
Its & 11 & 5 \\
Our & 5 & 5 \\
Their & 19 & 15 \\
\hline
\end{tabular}

\section{Sentence Structure}

Sentence structures are another Nord's criterion based on which the translation is analyzed. One very significant criterion, according to Nord (2005) is the length and number of the words and sentences in the original and the translated texts. For extracting the number of sentences, the Sketch engine was exploited which is a corpus software tool. The following table represents the related information

Table 3. The Basic Information of the Two Texts

\begin{tabular}{cll} 
English Sentences & Tokens & Words \\
\hline 1,418 & 21,751 & 17,112 \\
Persian Sentences & Tokens & Words \\
\hline 643 & 16,880 & 14,575 \\
\hline
\end{tabular}

As the table 3 represents, the two texts differ in terms of tokens and words which indicates that the two texts, although are of the same prose style, differ in the way the words and structures are used. Moreover, most sentences in both texts have been written by the active structure which shows that the writer and the translator highlight the role of the agency in their writing.

Examples:

I showed my masterpiece to the grown-ups شاهكار ر ا نثان بزركتر ها دادم

I made another drawing: I drew the inside of a boa Constrictor نقاشى ديكرى كثيدم. من درون يكى مر ار ا رسم كردم

I have serious reason to believe that... 
من دلايل جدى دارم كه باور كنم...

I have suffered too much grief

غمزيادى را تحمل كرده ام

\section{Suprasegmental Features}

The Suprasegmental features of a text are referred to the elements that "overlap the boundaries of any lexical or syntactical segment, sentences and paragraph" (Nord, 20005, P. 132). One very important of Suprasegmental features of any text is the usage and application of cleft-sentences. As the data show, the English text has more than 348 items of Suprasegmental features. This trend shows that the author has put too much attention on the cleft-sentence structure.

Examples:

It was a picture of a boa constrictor in the act of swallowing an animal

It was a question of life or death for me: I had scarcely enough drinking water to $\underline{\text { last a week }}$

It was that of the boa constrictor from the outside.

But he was in Turkish costume, and so nobody would believe what he said

\section{Discussion and Conclusion}

Translation functionalism is classified into those theories of translation which define translation as a product-oriented process, in accordance with the requirements of the commissioner and the target text receiver. To this end, this study was an attempt to analyze a case study in terms of functionalism in translation. For this purpose, an English novel together with its Persian translation was selected. For the theoretical framework, Nord's model of documentary vs. instrumental translation was selected. This model of text analysis requires both external and internal investigation of the elements by which texts are organized. The internal analysis features are subject matter, content, presupposition, text composition, non-verbal elements, lexis, sentence structure and Suprasegmental features. The external features include sender, sender's intention, medium, place of communication, time of communication, motive for communication, receiver, audience and text function.

As far as the external analysis is concerned, it seems that the two texts differ in some factors and this had impacts on the translation. As far as the medium is concerned, it 
is clear that the target text (Persian translation) has more pictures than that of the source text which indicates some sort of manipulation. Also, due to the pictures, the target text is smaller than the source text, 64 vs. 43 pages, respectively. In addition, in terms of the Sender's intention and the subject matter of the target text, however, the two texts peruse the same purpose which is to entertain the readership. In other words, the main characteristic of the two texts is purpose preserving.

In terms of place and time of the publication, it is conspicuous that the two texts differ. The English version of the book was published in England in 1943; while its Persian translation was published in Iran in 1984; that is to say, 39 years after the English text was written, However, as far as the motive of the communication is concerned, it can be understood that the two texts do not share the same motivations which can be stem from the fact that they might have had different worldviews and perspectives.

When it comes to text functions, it seems that while both texts belong to children literature and enjoy to a great extent, creative writing and composition, the target text is more prose-oriented than the source text which makes it more readable and more interesting for them. It shows that the two texts have some differences in terms of text functions.

For the internal factors, the two texts also represent some great amount of divergence. As far as the presupposition is concerned, the text analysis showed that the two texts belong to the category of fictional texts. For the lexis part, the source text used in the first person narration which requires the extended use of personal pronoun, however, the Persian translation differs. Sentence structure also shows that the two texts differ extensively in terms of the number of words and sentences. The last, but not the least feature which is Suprasegmental features indicate that the source text had exploited the cleft sentences in a number of different ways.

Overall, the analysis of external and internal features of the source text and the target text above the sentence level can show that the translator to a great extent used the instrumental translation and the translation of the source text reads like an original in the source text culture. In other words, the target text functioned as an independent message based on the constraints of the target text and it is written in such a way that the readers would perceive it as an original work in Persian.

\section{Implications, Limitations, and Suggestions for Further Research.}


This study has some implications for those who are interested in translation. One implication is for translation researchers and critics. This study is useful for them in a sense that it is a practical example of Nord's dichotomy and they can be familiarized with the practical steps towards this text analysis model. Another implication is for translation instructors. They can use the findings of this study to familiarize the students with different models of translation. This study has implications for translation students as well. Students in the field of translation can use the findings of this study to be familiarized with the nuances of translation practice.

Like any other study, this study suffered from some limitations some of which could negatively impact the findings. One limitation was that the original text was written in French and since the author had no knowledge of French language, he had to rely on the English version of the text. The other limitation was that a review of the literature revealed that this model had not been into practice in an English- Persian context; therefore, it was difficult to refer to the studies done before.

This study has some suggestions for further researches. Another study can be done with a broader corpus. For example, one can choose three to five books as the corpus of the study and applies this model to them. Also, another study can be done in English translations of Persian novels to detect the examples of this dichotomy in English translation. Further, some other studies can be done by comparing two or three translations of one specific book to see if they are documentary oriented or instrumental oriented.

\section{References}

As-Safi, A. (2011). Translation theories: Strategies and basic theoretical issues. Amman: Amwaj.

Aveling, H. (2002). Mistakes in translation: A functionalist approach. A Paper Prepared for the Third Workshop on The Art of Translation. London: UK.

Boushaba, S. (1988). An Analytical Study of Some Problems of Literary Translation: A

Study of Two Arabic Translations of K. Gibran's The Prophet. Unpublished Ph. D Dissertation, The University of Salford, UK.

Bühler, K. (1990). Theory of language: The representational function of language. Amsterdam: J. Benjamins Pub.

Catford, J. C. (1965). A linguistic theory of translation; an essay in applied linguistics. London: Oxford University Press.

Chang, J.-F. (2007). The Role of Children's Literature in the Teaching of English to Young Learners in Taiwan. Unpublished Ph. D Dissertation, The University of Waikato, Hamilton, New Zealand.

Coillie, J. V., \& Verschueren, W. (2006). Children's literature in translation: Challenges and strategies. Manchester, UK: St. Jerome Pub. 
Devi, R., \& Panda, A. (2015). The Skopos Theory: A Heterogeneous Approach to Translation. American International Journal of Research in Humanities, Arts, and Social Sciences, 9(3), 281-283.

Dewi, M. F., Maulia, L., \& Citraresmana, E. (2014). The Equivalence and Shift in the Indonesian Translation of English Adjective Phrases. Research on Humanities and Social Sciences, 4(11), 109-113.

Hollindale, P. (1997). Signs of childness in children's books. Stroud: Thimble.

Holz-Manttari, J. (1984) Translatorisches Handeln: Theorie und Methode, Helsinki: Suomalainen Tiedeakatemia.

House, J. (2001). Translation Quality Assessment: Linguistic Description versus Social Evaluation. Meta Meta: Journal Des Traducteurs, 46(2), 243. doi:10.7202/003141ar House, J. (2015). Translation Quality assessment: Past and Present. London \& NewYork: Routledge.

Jabir, J. K. (2006). Skopos Theory: Basic Principles and Deficiencies. Journal of the College of Arts. University of Basrah, (41), 37-46.

Kerr, G. J. (2011). Dynamic equivalence and Its daughters: Placing Bible Translation Theories in Their Historical Context. Journal of Translation, 7(1). Kolawole, S. O. (2013). Functionalist theories and their relevance to Yoruba bible translation. Time Journals of Arts and Educational Research,1(13), 13-20.

Kriston, A. (2014). An Approach to Business Translations. A Functionalist Translation. Scientific Bulletin of the Polytechnic University of Timişoara Transactions on Modern Languages, 13(1), 31-38.

Lathey, G. (2006). The translation of children's literature: A reader. Clevedon: Multilingual Matters.

Lathey, G. (2006). The Role of Translators in Children's Literature: Invisible Storytellers. Gillian Lathey. London and New York: Routledge.

Molina, L., \& Albir, A. H. (2002). Translation Techniques Revisited: A Dynamic and Functionalist Approach. Meta: Journal des traducteurs, 47(4), 498-512. doi:10.7202/008033ar.

Munday, J. (2001). Introducing translation studies: Theories and applications (1st ed.). London: Routledge.

Munday, J. (2012). Introducing translation studies: Theories and applications (3rd ed.). London: Routledge.

Munday, J. (2016). Introducing translation studies: Theories and applications (4th ed.). London: Routledge.

Newmark, P. (2009). The linguistic and communicative stages in translation theory. In Routledge companion to translation studies (20-36). USA and Canada.

Nida, E. (1945). "Linguistics and Ethnology in Translation Problems," Word 1: 194-208. Nida, E. A and C. R. Taber (1969). The Theory and Practice of Translation, Leiden: E. J. Bill.

Nord, C. (1991). Text analysis in translation: theory, methodology, and didactic application of a model for translation-oriented text analysis. Amsterdam/New York, NY: Rodopi.

Nord, C. (1997). Translation as a purposeful activity: Functionalist approaches explained. Manchester, UK: ST. Jerome.

Nord, Ch. (2001). Text Analysis in Translation. Beijing: Foreign Language Teaching and Research Pres.

Nord, C. (2006). Text analysis in translation: theory methodology, and didactic application of a model for translation-oriented text analysis. Amsterdam: Rodopi. 
Nord, C. (2010). Functionalist approaches. Handbook of Translation Studies, 120-128. doi: 10.1075/hts.1.fun1

Palumbo, G. (2009). Key terms in translation studies. London: Continuum.

Panou, D. (2013). Equivalence in Translation Theories: A Critical Evaluation. TPLS Theory and Practice in Language Studies, 3(1). doi:10.4304/tpls.3.1.1-6

Pitra, G. (2006). Why does children's literature need translation? (19-33). In Children's literature in translation: Challenges and strategies. Manchester, UK: St. Jerome Pub.

Pym, A. (2010). Exploring translation theories. London: Routledge. Snell-Hornby, M. (2006). The turns of translation studies: New paradigms or shifting viewpoints? Amsterdam: J. Benjamins Pub.

Shuttleworth, M., \& Cowie, M. (1997). Dictionary of translation studies. Manchester, UK: St. Jerome Pub.

Sokolovsky, Y. V. (2010). On the Linguistic Definition of Translation. Journal of Siberian Federal University. Humanities \& Social Sciences, 2, 285-292.

Superceanu, R., Translating Pragmatic Texts. Timişoara: Editura Orizonturi universitare, 2009.

Venuti, L. (2012). The translation studies reader. London; New York: Routledge, 2000.: Routledge.

Vermeer, H.J., A Skopos Theory of Translation (some arguments for and against). Heidelberg: Text context Verlag, 1996.

Williams, J. (2013). Theories of translation. Surry: UK: Macmillan.

Xiang, Y. (2011). Dynamic Equivalence: Features and Merits. TPLS Theory and Practice in Language Studies, 1(9), 1253-1255. doi:10.4304/tpls.1.9.1253-1255

Xuedong, S. (2014). Cross-Cultural Communication. A Study on English-Chinese News Translation from the Perspective of Functionalism, 10(3), 89-95. doi:10.3968/4493.

Yi, Z. (2013). Communicative Purposes in Translational Activities: A Functional Study on Target Prefaces and Postscripts. Intercultural Communication Studies, XXII (2), 7590.

Yue, S. (2013). Functionalism Theory Applied in C-E Translation of Chinese Food Culture Text. Theory and Practice in Language Studies, 3(1), 61-68. doi:10.4304/tpls.3.1.6168

Yule, G. (2010). The study of language. Cambridge, UK: Cambridge University Press. 